\title{
Präzise Diagnostik und optimale Planung führen zum Therapieerfolg
}

Am 17. Juni versammelte Oral-B über 400 Zahnärzte und Prophylaxe-Fachkräfte, um das vielschichtige Thema PatientenCompliance mit namhaften Referenten zu diskutieren. Unter dem Motto „CHANGE YOUR MIND - Veränderung beginnt im Kopf" bot das 6. Oral-B Symposium im World Conference Center in Bonn ein interessantes und abwechslungsreiches Rahmenprogramm mit Vorträgen, Workshops und einem interaktiven Erlebnisbereich. Für die Teilnehmer bestand zudem die Möglichkeit, die Oral-B Weltneuheit GENIUS in einem Produkterlebnisbereich kennenzulernen. Das intelligente Zahnputz-System kombiniert die einzigartige Positionserkennungs-Technologie mit einer 3-fachen Andruckkontrolle und einem professionellen Timer - für eine Zahnpflege-Routine wie vom Zahnarzt empfohlen. Erstmals bietet eine elektrische Zahnbürste in Kombination mit der neuen Oral-B App 4.1 die Möglichkeit der Positionserkennung und eröffnet so eine neue Ära in der interaktiven Zahnpflege. Durch die Sensoren im Handstück der
Zahnbürste, die jede Putzbewegung erkennen, und einer Bildanalysefunktion des Smartphones, kann in Echtzeit

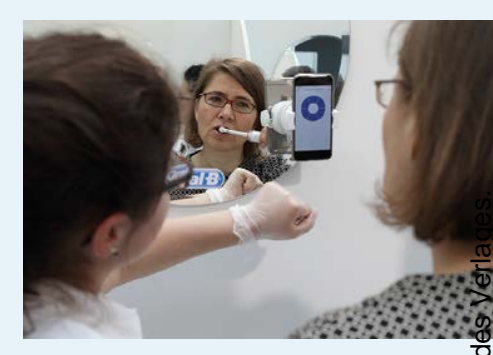
verfolgt werden, wo bereits geputzt wurde und wo einzelne Bereiche ausgespart wurden. Das Datenmaterial kann darüber hinaus direkt in der App gespeichert, digital an den Zahnarzt übermittelt und im Rahmen eines persönlichen Praxistermins besprochen werden. Basierend auf den gespeicherten Putzdaten sowie den individuellen Bedürfnissen der Patienten kann der Zahnarzt oder die Prophylaxe-Fachkraft spezielle Putzempfehlungen und -ziele direkt in die App einprogrammieren.

Nach einer Pressemitteilung der Procter \& Gamble GmbH, Schwalbach am Taunus 